\title{
Graham, Stephen. Cities under siege. The new military urbanism. (Londres: Editorial verso, 2010).
}

Milton José Reza Rivas

Universitat Autónoma de Barcelona
"Cities under siege. The new military urbanism" es el resultado de un trabajo científico-social crítico realizado por Stephen Graham $^{2}$. Este autor se ha especializado en el estudio de las ciudades y la vida urbana, y es profesor en la escuela de arquitectura, planificación y paisajismo de la Universidad de Newcastle (Reino Unido).

El libro presenta los resultados de una investigación académica acerca de cómo, en los últimos años, muchos gobiernos han desarrollado políticas de infraestructuras que propenden a la incorporación de cuestiones urbanas dentro de la doctrina militar, permitiendo que las fuerzas de seguridad castrense y civil invadan el paisaje de las ciudades.

\footnotetext{
${ }^{1}$ En español: "Ciudades bajo asedio. El nuevo urbanismo militar".

2 Para más información acerca del Prof. Graham, véase http://www.ncl.ac.uk/apl/staff/profile/stevegraham.html\#backgrou nd. Fecha de revisión: 18/02/2016.
}

La obra presenta una visión global sobre temas conceptuales y empíricos: por un lado, examina la dimensión teórica del nuevo urbanismo militar, y por otro ofrece un estudio detallado de casos que ponen de relieve un examen crítico acerca de la violencia, el control y la vigilancia producto de una revolución de los medios digitales en la vida ciudadana que impregna a los espacios cotidianos, lugares y vías de circulación de las ciudades superpobladas.

Así pues, el autor inicia su argumentación explicando cuál ha sido el sentido y el alcance que la mayoría de los gobiernos otorga a la política de militarización del paisaje urbano. En ese orden, la define como una constelación de ideas, técnicas y normas de seguridad y doctrina militar que procura penetrar progresivamente el tejido de las ciudades.

Esta militarización introduce un nuevo paradigma dentro de la gestión pública, que entiende a los enclaves citadinos contemporáneos 
como los centros estratégicos clave en los que las fuerzas armadas y de seguridad son rediseñadas para controlar sus infraestructuras, habida cuenta que en su interior se encuentran una amplia gama de amenazas en contra de la propia estabilidad del orden local y mundial.

En ese sentido, el poder constituido asume a las ciudades como auténticas zonas de guerra, viéndose forzado a redirigir gran parte de los recursos estatales para rediseñar sus áreas y permitir que en ellas se ejecuten políticas de seguridad preventiva que desplieguen vigilancia electrónica, recopilación de inteligencia, operaciones de contrainsurgencia y control de las poblaciones civiles que permitan alcanzar niveles mínimos de riesgos, que otrora tuvieron dimensión local y que ahora adquieren una extensión global.

Dicha estrategia es puesta en práctica a través de organismos policiales dotados, en gran parte, de soldados rurales desplegados en zonas urbanas infectadas de amenazas múltiples, y engendra además una noción particular de guerra caracterizada por el ejercicio permanente del monopolio de la violencia del Estado y $\sin$ límites, haciendo uso de alta tecnología y expandiendo cada vez más operaciones de seguridad -con apoyo de investigadores del sector privado y de corporaciones militares- en contra de una amplia variedad de adversarios no estatales que se asientan en dichas ciudades junto con el resto de habitantes.

Así pues, la militarización de las áreas urbanas pasa a elevar drásticamente los niveles de desintegración del espacio que separa la política de lo castrense, haciendo que los ciudadanos lleguen a aceptar, o incluso a considerar como necesaria, la presencia de la doctrina marcial en la lógica de la vida cotidiana.

En este sentido, valdría la pena destacar opiniones como la de Amnistía Internacional, quien mediante informe publicado en septiembre de 2014 titulado "The Future of Human Rights in an Urban World. Exploring Opportunities, Threats and Challenges"3, no sólo secunda las teorías planteadas por Graham, sino además recalca como hoy en día todos nos estamos acostumbrando a encontrar cada vez más aspectos tecnológicos e ideas militares dentro del espacio civil. Esta presencia contribuye a que las personas percibamos como "normal" aquella reorganización doméstica del espacio de las ciudades en la que se despliegan tecnologías de guerra que pasan por el levantamiento de muros fronterizos $^{4}$, la multiplicación de puntos de

\footnotetext{
${ }^{3}$ En español: "El futuro de los derechos humanos en un mundo urbano. La exploración de oportunidades, amenazas y desafios”. Documento disponible https://www.amnesty.nl/sites/default/files/public/the future of hu man rights in an urban world 0.pdf. Fecha de revisión: $18 / 02 / 2016$

${ }^{4}$ Un ejemplo de ello se observa en promesas electorales como las dada por el Presidente electo de los Estados Unidos de
} 
controles biométricos y el uso de vehículos de vigilancia aérea no tripulados ${ }^{5}$.

Al hilo de las aportaciones de Graham, los geógrafos británicos JONAS, A., McCANN, E. y THOMAS, M. $(2015)^{6}$ mediante su libro "Urban Geography: a Critical Introduction" reafirman que en la actualidad la mayor parte de la vigilancia policial selectiva en las zonas domésticas urbanas es llevada a cabo por personas sometidas a un entrenamiento militar, a menudo perfeccionado en el extranjero y a través de procesos de formación y capacitación previa y/o posterior a un conflicto armado.

En ese sentido, como bien señala Graham, el actual modelo de diseño urbano se basa invariablemente en la normalización de los paradigmas castrenses de pensamiento, acción y política; de intentos de disciplina agresiva de los cuerpos, los lugares y las identidades que no se

Norteamérica, Donald Trump, quien prometió construir un muro de separación con México durante los primeros cien días de su gestión en la Casa Blanca, ya que en su opinión dicho muro sería un catalizador de su nueva política contra la inmigración ilegal, que pretende ser muy restrictiva. Para más información Vid. artículo titulado "Donald Trump promete unas puertas "grandes" $y$ «bonitas» en su muro con México", publicado el 10/02/2016 en la edición electrónica del periódico $\mathrm{ABC}$ Internacional, disponible en: http://www.abc.es/internacional/abci-donald-trump-prometeunas-puertas-grandes-y-bonitas-muro-mexico-

201612100449 noticia.html. Fecha de revisión: 13/10/2016.

${ }^{5}$ Vid. HAYES, B., JONES, C. y TRÖPER, E. "Eurodrones Inc.", reporte publicado por the Transnational Institute and Statewatch, Ámsterdam, Países Bajos, 86 pp.

${ }^{6}$ En español: "Geografía Urbana: una introducción crítica". Datos bibliográficos: JONAS, A., McCANN, E. y THOMAS, M. Urban Geography: a Critical Introduction, Oxford, Reino Unido, Editorial Wiley Blackwell, 2015, 398 pp. ajusten a las nociones frecuentemente masculinizadas de nación y ciudadanía; y del despliegue de material propagandístico que idealiza a la violencia como un medio estatal para la justa venganza o alcanzar un propósito dado por Dios.

Esta nueva visión de gestión pública en las ciudades llega incluso a torcer los actos sociales más prosaicos, ya que en su conjunto sume a la vida urbana en un existencialismo interno, en razón del asedio de amenazas sociales y miedos en los que fenómenos como la inmigración, el refugio o los desplazamientos, puedan llegar a considerarse auténticos actos de riesgo o de combate en el marco de una guerra de cuarta generación, híbrida, conflicto bélico no convencional, lucha asimétrica, insurgencias globales o de baja intensidad.

Dicho contexto es abordado por Graham de manera amplia, a través de un estudio histórico-descriptivo. En su libro, nos presenta así un análisis pragmático del urbanismo militar y lo explica cómo el nuevo paradigma de control y vigilancia estatal que surge en respuesta a una situación de tiempo, modo y lugar que los gobiernos del mundo no pueden obviar.

Graham alude que luego de los ataques terroristas del 11 de septiembre de 2001 en los Estados Unidos de Norteamérica, una sensación de miedo, desolación y terror generalizado se ha 
apoderado del imaginario colectivo de la humanidad, especialmente en razón de posteriores atrocidades similares perpetradas por grupos terroristas en las ciudades de Madrid, Londres o Mumbai (por tan sólo enunciar otros sitios de ataque), que luego justificaron el despliegue de medidas contraofensivas de asalto militar por parte de coaliciones gubernamentales en lugares como Bagdad, Gaza, Nablus, Beirut, entre otras ${ }^{7}$.

En razón de ello, los perjudicados directos de tan abominables sucesos se convierten en un mero instrumento de los terroristas, a través del cual logran comunicar un mensaje claro que evoque la transferencia indiscriminada de un estado de miedo extremo y sufrimiento a una audiencia separada y más amplia que, desde la lógica del agente terrorista, debe intimidarse y subyugarse ante el terror.

\footnotetext{
7 Contextos más recientes que podemos destacar a título referencial serían el ataque terrorista múltiple cometido en la ciudad de París (Francia) el pasado 13/11/15 y en Bruselas (Bélgica) el 22/03/2016, ambos llevados a cabo por el grupo yihadista Daesh (Acrónimo árabe del autodenominado Estado Islámico), en el que murieron más de un centenar de personas y que ha traído como consecuencia la declaratoria de guerra total por parte del gobierno francés y belga en contra de dicho grupo insurgente, así como, en razón del primero de los ataques referido, una condenatoria al terrorismo por parte del Consejo de Seguridad de las Naciones Unidas, quien mediante resoluciones Nro. 2249, 2253 y 2255 del año 2015, permite que cualquier país del mundo pueda desplegar su potencial armamentístico para la erradicación de ese fenómeno y siempre en ejercicio de la legítima defensa o a través de intervenciones hechas por invitación del Estado que corresponda. Más información, se encuentra disponible a través del enlace: http://www.un.org/en/sc/documents/resolutions/2015.shtml. Fecha de revisión: 23/03/2016.
}

Así pues, la población urbana se ve sugestionada/inducida a replantear su convicción hacia el orden económico, político, social y jurídico establecido, en tanto que el propio poder constituido pasaría a ser considerado como un responsable directo de la ejecución de tan lamentables sucesos, en virtud de su incapacidad, negligencia, imprudencia u omisión de resguardo de la población frente a la dimensión del riesgo que representa el fenómeno terrorista.

Ahora bien, más allá del método empleado, cualquier ejercicio de la violencia generalizada e ilegal, ejecutada por organizaciones armadas insurgentes, milicias o vandalismo, lo que pretende es debilitar el monopolio estatal sobre la violencia, para precipitar el cambio de lealtades entre grupos societarios, demostrar un poder de influencia colectiva que les permita a sus agentes establecer alianzas con una $\mathrm{u}$ otra parte de la población, afectando en definitiva las relaciones del propio Estado con su pueblo.

Ante este panorama, muchos especialistas en seguridad global ${ }^{8}$ defienden así la puesta en marcha de estrictas políticas gubernamentales de

\footnotetext{
${ }^{8}$ Para más información sobre esta tendencia académica, véase el artículo al cual refiere el profesor Graham en la introducción de la obra, escrito por los estadounidense Mark Mills y Peter Huber y publicado en el City Journal con motivo a los ataques terroristas del 11/09/2001 en USA, titulado "How Technology Will Defeat Terrorism", disponible en http://www.cityjournal.org/html/12 1 how tech.html. Fecha de revisión: $18 / 02 / 2016$.
} 
vigilancia y seguimiento, desarrolladas mediante complejos sistemas tecnológicos que protejan preventivamente a las ciudades de cualquier ataque, abarcando para ello el uso provechoso de altas tecnologías de consumo, movilidad, comunicación y transporte, especialmente en las sociedades occidentales.

Teóricos marciales, e incluso comandantes de las fuerzas armadas de occidente, apuestan por la necesidad de planear estrategias de seguridad y defensa ante cualquier batalla que se suscite en las áreas urbanas, dirigiendo la infraestructura civil y la economía destrozada, fortaleciendo la conciencia cultural de los problemas que aparentemente amenazan a los ciudadanos y aplicando la violencia controlada para intentar alcanzar niveles óptimos de seguridad.

Prueba de estas premisas planteadas por Graham la podemos encontrar actualmente, por ejemplo, en distintos reportes de la Organización del Tratado del Atlántico Norte (OTAN), quien desde el mes de noviembre del año 2010 acordó la ampliación del concepto estratégico de defensa y seguridad de sus Estados miembros ${ }^{9}$, alentando el desarrollo de nuevas tecnologías -armas láser, de guerra y aquellas que impidan el acceso al

9 Documento disponible a través del enlace: http://www.nato.int/strategic-

concept/pdf/Strat Concept web en.pdf. Ver párrafos 04, 05 y 14. Fecha de revisión: 23/03/2016 espacio electrónico- en el marco de la planificación y el despliegue de fuerzas militares robustas, dentro y fuera de sus fronteras, que garanticen la seguridad compartida entre sus comunidades -ciudades- guiada por los valores de libertad y de paz.

En ese mismo sentido nos encontramos con el reciente reporte aprobado por la Unión Europea acerca de su nueva estrategia global para las políticas exteriores y de seguridad, en el que establece que los medios de defensa y resguardo de la Unión se han de desarrollar con máxima interoperabilidad y uniformidad, en apoyo de la OTAN, las Naciones Unidas y otras iniciativas multinacionales. Es una estrategia sectorial que apuesta por la inversión, el desarrollo y la innovación de capacidades de nivel cívico-militar, haciendo énfasis en los campos de la biotecnología, la inteligencia artificial, la robótica y los sistemas pilotados a distancia, para evitar los riesgos de seguridad conexos y aprovechar sus beneficios económicos ${ }^{10}$.

Por su parte, autoridades del gobierno de los Estados Unidos de Norteamérica, mediante la sección 332 del 01/02/2012, dictó un acto de Ley que permite la reforma y la modernización de la

\footnotetext{
${ }^{10}$ MOGHERINI, F. "Shared Vision, Common Action: A Stronger Europe. A Global Strategy for the European Union's Foreign and Security Policy", Comisión Europea, Bruselas, Bélgica. Junio, 2016. $60 \mathrm{p}$.
} 
Federación Federal de Aviación ${ }^{11}$, el cual ordena desarrollar un plan integral para acelerar de forma segura la integración de sistemas de aeronaves no tripuladas civiles en el sistema nacional de espacio aéreo americano.

Asimismo, el Departamento de Seguridad Nacional de dicha potencia americana ${ }^{12}$, refrendó los esfuerzos en utilizar nuevas tecnologías como método de vigilancia y control de las ciudades, para impedir los cruces fronterizos ilegales por parte de extranjeros no autorizados, criminales y terroristas, y detectar, además de prohibir, el comercio criminal de armas, drogas y otros tipos de contrabando en el país.

Así pues, todos los ejemplos supra destacados nos muestran cómo durante los últimos años varios gobiernos del mundo han pretendido legitimar el despliegue estatal de una continua y automatizada guerra contrainsurgente, en la que enjambres de guerreros robotizados equipados con sensores avanzados y comunicados entre sí trabajen intensamente en proyectar a distancia un poder destructivo, de

11 Documento disponible a través del enlace: https://www.gpo.gov/fdsys/pkg/CRPT-112hrpt381/pdf/CRPT-

112hrpt381.pdf. Cualquier información sobre los informes técnicos más importantes analizados por el Congreso de los Estados Unidos de Norteamérica acerca de la vigilancia y control doméstico con nuevas tecnologías y su repercusión frente a la Cuarta $\quad\left(4^{\mathrm{a}}\right) \quad$ Enmienda, ver el enlace: https://www.fas.org/sgp/crs/natsec/R42701.pdf. Fecha de revisión: 23/03/2016.

12 Documento disponible a través del enlace: https://www.dhs.gov/securing-and-managing-our-borders. Fecha de revisión: 23/03/2016. inteligencia $\mathrm{y}$ de control represivo, e indiscriminado, sobre grupos irregulares insertos en las sociedades, aún y cuando ello pueda afectar el conjunto de libertades básicas de los ciudadanos, puesto que el fin primordial del Estado es, y será, salvaguardar el "bien común".

En ese sentido, las ciudades contemporáneas entran en un proceso de urbanización de la guerra, siendo consideradas incluso un caldo de cultivo para potenciales conflictos violentos en las naciones, y entre las naciones, lo cual habilita a los gobiernos a controlar sus fronteras, verificar en detalle los flujos migratorios para alcanzar la separación entre el riesgo y sus víctimas.

Con ello queda instaurada una espiral de acción/represión/reacción, mediante la adopción de mandatos políticos, legislativos y policiales excepcionales por parte del poder constituido, en el marco de una gestión de seguridad global acompañada de cooperación internacional, que valora la ubicuidad de los límites fronterizos y asume el paradigma de una vigilancia urbana omnisciente dentro y fuera de los EstadosNación, todo en aras de reducir los escenarios de oportunidad a cualquier repertorio violento $\mathrm{y}$ desestabilizador del orden legítimo.

Es la puesta en marcha de una arquitectura organizacional globalizada que justifica la permanente colonización estatal de los 
paisajes ciudadanos y los espacios del día a día mediante la reubicación social de sus ciudadanos en razón de criterios socio-económicos, marcadores étnico-raciales o religiosos, y la aplicación de técnicas militares para el seguimiento y la selección de objetivos, tanto en los países donde estas se originan como más allá de sus fronteras mundiales neocoloniales.

Es una arquitectura urbana desarrollada en el marco de poblaciones diversas cuyas inseguridades (especialmente la de sus miembros más desfavorecidos y socialmente excluidos) facilitan la receptividad colectiva de ideologías y movimientos radicales violentamente antioccidentales, y convierten a sus asentamientos marginales en lo que algunas élites políticas, empresariales y militares denominan áreas "informales y existenciales", de niveles subhumanos, que amenazan al "archipiélago" de privilegios urbanos que giran en torno a la economía formal, el turismo, la producción y el transporte.

La disparidad y consecuente sectorización de grupos societarios, somete a los espacios urbanos, sus símbolos, significados, sistemas de soportes y estructuras de poder, a un mundo regido por la dicotomía de la construcción maniquea del "nosotros" y los "otros", fortalecida a través de discursos, posiciones, consignas y demandas -políticas o insurgentes- en todo el mundo que han hecho imposible la consolidación definitiva de civilizaciones homogéneas y multiculturales.

Así pues, las ciudades pasan a ser áreas de lucha entre el bien y el mal, un escenario de repudio y combate entre dos visiones antagónicas sobre el deber ser, esto es, la de aquellos que se oponen el orden establecido y la de los que tradicionalmente dirigen o se benefician de este.

En ese contexto, las fuerzas de seguridad estatales y las corporaciones privadas ven la oportunidad de demoler todo asentamiento existencial $^{13}$, para luego crear modernas infraestructuras y desarrollos urbanísticos o, simplemente, ubicar a esas poblaciones conflictivas fuera de la vista de los enclaves citadinos en los que sí se encuentran muchos de los privilegios urbanos.

Al ser ello así, el autor destaca una verdad probablemente incuestionable: si el punto de la guerra contra el terrorismo o cualquier otra forma ilegal de violencia generalizada estriba en perseguir al enemigo dentro de su propio laberinto cultural y sociológico, resulta evidente que las periferias empobrecidas emergentes o aquellas construidas en las ciudades en desarrollo

\footnotetext{
13 También conocidas como infraviviendas o establecimientos irregulares (chabolas), en donde se sitúa una persona o una comunidad que no está dentro del margen de los reglamentos o las normas establecidas por las autoridades encargadas del ordenamiento urbano.
} 
pasarán a ser las nuevas y permanentes zonas de batallas del siglo XXI.

Ejemplos que ilustran esta realidad lo podemos encontrar en localidades como Molenbeek (Bélgica) o el suburbio parisino de Saint-Denis (Francia), lugares en los que actualmente se vienen desplegando rigurosas operaciones militares y policiales coordinadas simultáneamente entre varios gobiernos afectados por el terrorismo global, a los fines de ubicar y erradicar células yihadistas que han planificado y ejecutado atentados como el ocurrido el 11 de marzo de 2004 en la ciudad de Madrid (España) o los ataques suicidas del 13 de noviembre de 2015 en la ciudad de Paris (Francia).

En estos enclaves “problemáticos", la violencia del Estado se utiliza para fomentar "la depredación militarizada y neocolonial" de los recursos necesarios (propios y distantes) para el sostén de las ciudades occidentales más ricas y los estilos de vida que estas representan.

Con este tipo de políticas, las ciudades quedan sometidas a una situación de asedio, mediante la implementación de nuevas técnicas y tecnologías de represión colonial urbana, que hacen recorrido de ida y vuelta entre las fronteras coloniales y los bastiones metropolitanos europeos.
Es un proceso interdependiente que, en referencia a Foucault, Graham conceptualiza como especie de "efecto búmeran"14 que propende a unir la seguridad y la doctrina militar del oeste con sus "periferias coloniales", respaldado por culturas geográficas que acogen políticas de derecha y de extrema derecha junto con el núcleo duro del poder militar occidental.

Esta teoría busca demostrar cómo los aparatos, las instituciones y las técnicas de poder propias de Occidente, que en su momento han intentado transferir modelos propios a otras partes del mundo mediante la colonización, han sufrido efectos de retorno que modifican sus propias técnicas y armas jurídico-políticas.

Según la obra comentada, varios casos paradigmáticos ilustran empíricamente dicho efecto de "búmeran”. A título enunciativo, vale la pena destacar, por ejemplo, el uso de unidades aéreas no tripuladas con armas no letales, que originariamente han sido desarrolladas en Israel, pero que hoy en día son utilizadas por agencias policiales de USA, Europa y Asia; otro caso sería aquellas situaciones en las que ciertos gobiernos occidentales ponen en práctica técnicas de construcción de áreas de seguridad militar, como

\footnotetext{
14 Terminología usada por el filósofo Michel Foucault. Al respecto, véase las transcripciones del curso por este académico en el Collège de France, entre finales de 1975 y principios de 1976. Quinta lección, página 89. Datos bibliográficos: FOUCAULT, M., Genealogía del racismo. De la guerra de las razas al racismo del Estado, La Plata, Argentina, Editorial Altamira, 1996, 220 pp.
} 
la zona verde de Bagdad $^{15}$-resultado de intereses geoestratégicos de protección-, para resguardar así núcleos financieros en las ciudades de Londres y Nueva York.

Ahora bien, de una manera u otra, la mayoría de los gobiernos en el mundo se ven en la necesidad de apostar por una revolución en los asuntos militares que permita el uso de nuevas tecnologías de vigilancia, comunicación, acciones furtivas o precisión de objetivos, mediante armas inteligentes que alcancen la expansión global de la omnipotencia militar de occidente, basada en una interconexión propia de una guerra centrada en redes ${ }^{16}$.

Es una visión geopolítica de vigilancia y control que existe en los grupos tecnocientíficos destinados a alcanzar soluciones a potenciales riesgos globales que subyacen en las ciudades, $y$ que además traen consigo una política de tolerancia cero que pretende excluir de las zonas

\footnotetext{
${ }^{15}$ Es un término de origen militar que hace referencia a la zona más segura de Bagdad después de la invasión de Iraq de 2003. Esta es un área fortificada donde se encuentran los edificios del gobierno de Irak, las bases de la coalición y la mayoría de las embajadas.

${ }^{16}$ Esta doctrina militar apunta a convertir una ventaja informativa en una ventaja competitiva mediante una sólida red de fuerzas, geográficamente dispersas, pero bien conectadas e informadas. Dicho concepto tiene su origen en febrero de 1996, a raíz de un artículo elaborado por el Almirante William A. Owens titulado "The Emerging U.S. System-of-Systems", y que fue publicado por el Instituto Nacional de Estudios Estratégicos en los Estados Unidos de Norteamérica. En este artículo, Owens introduce la idea de un emergente "sistema de sistemas", impulsado en parte por las arquitecturas de los propios sistemas generales y los conceptos operativos conjuntos. Artículo disponible a través del enlace: file:///C:/Users/rimej 000/Downloads/ADA394313.pdf. Fecha de revisión: 23/03/2016.
}

de ocio y consumo a todas aquellas personas que previamente queden etiquetadas como "indeseables".

Frente a este panorama, Graham enfatiza la necesidad de promover la existencia de un contrapoder, que no sólo equilibre la hegemonía del actual orden constituido, sino que además contribuya a la consolidación de un buen urbanismo que vaya más allá de las afirmaciones del cosmopolitismo y de la democracia, y que permita la participación y colaboración de los receptores mediatos e inmediatos de la violencia extrema que trae consigo el urbicidio $^{17}$, la imposición del fundamentalismo neoliberal despiadado y la propagación de las encarcelaciones en masa.

\section{Graham utiliza una visión unificadora en} la que identifica los modelos urbanísticos como la clave para producir y organizar el espacio de las ciudades, sólo en tanto que esta encuentre su razón de ser en el contenido de las demandas, luchas, resistencias sociales y contrageografías ${ }^{18}$

\footnotetext{
${ }^{17}$ Dicho concepto comprende el despliegue de la violencia contra la ciudad a través de la reestructuración de los enclaves urbanos (y su destrucción). Para Graham, invocando la definición esbozada por Marshall Berman en 1982, considera que el urbicidio es la representación de una estrategia imperialista que deliberadamente busca la negación o el sacrificio de la ciudad mediante la devastación sistemática de los cascos urbanos, para luego en su lugar construir espacios y redes de modernidad que le conviertan en asentamientos relucientes. Para más información acerca del análisis de Berman, véase: BERMAN, M., Todo lo sólido se desvanece en el aire. La experiencia de la modernidad, Madrid, Siglo XXI de España Editores S.A., 1988, 386 pp.

18 Termino que alude a las nuevas redes alternativas y dinámicas que cambian -continuamente- las características de la localización,
} 
que se pueden ofrecer como respuestas al militarismo vigente.

Para ello, según el autor, las sociedades deben valerse de los métodos tradicionales de resistencia y movilización política que permitan rescatar el debate comunitario y garantizar la salvaguarda de los derechos humanos.

Estos métodos se encuentran hoy en día complementados por una variedad de redes $\mathrm{y}$ circuitos que recorren el mundo (tecnologías de comunicación e información) y que pueden llevar a un nivel superior cualquier escenario de lucha que pretenda subvertir la dicotomía de la construcción maniquea del "nosotros" y los "otros", así como el ideal occidental acerca de cuál es la manera en que debe establecerse la geografía de las ciudades, aspectos estos que en su conjunto imposibilitan a los ciudadanos obtener el efectivo domino de la vida pública urbana contemporánea.

Ahora bien, cualquier forma de rescate del poder debe forjar conexiones $y$ colaboraciones recíprocas entre las comunidades del mundo, las sociedades, los pueblos, creando nuevos espacios contrageográficos que permitan develar las auténticas razones económicas y políticas que subyacen ocultas en el desarrollo y establecimiento de una geografía para las ciudades impuesta por el nuevo urbanismo militar, incluso haciendo uso de las mismas tecnologías de vigilancia y de control que las políticas de seguridad castrenses despliegan en los enclaves citadinos y que hacen cada vez más ubicuas sus fronteras.

En suma, la obra apuesta por un rescate democrático, legítimo y coherente de la vida libre en las ciudades, un trabajo pertinente, necesario y diferente al habitual silencio de los ciudadanos, cuya actitud pasiva se ha combinado siempre con representaciones simbólicas que responden a intereses económicos, políticos y de corporativos privadas que allanan el camino del poder de penetración, asedio y reordenación militar de las ciudades.

y que comprenden un amplio margen de actividades que no son parte formal (o incluso de los objetivos) de la globalización, aunque están imbricadas en algunas de sus grandes dinámicas constitutivas. Para mayor profundización sobre el tema, véase el libro de SASSEN, S., Contrageograías de la globalización. Género y ciudadanía en los circuitos transfronterizos, Madrid, Editorial Traficantes de Sueños, 2003, 120 pp. 
